\title{
Factors influencing exclusive breastfeeding practices in rural areas in south Benin
}

\author{
Jahdiel Kossou ${ }^{1-3 *}$, Waliou Amoussa Hounkpatin ${ }^{1}$, Jaures Lokonon ${ }^{1}$, Clarisse Hounyo ${ }^{1}$, Aubierge Flenon ${ }^{1}$, Frejus \\ Goudjo $^{2}$, Sara Ait Lachguer ${ }^{3}$, Hasnae Benkirane ${ }^{3}$, Khalid El Kari ${ }^{3}$, and Hassan Aguenaou ${ }^{3}$ \\ ${ }^{1}$ School of Nutrition, Food Sciences and Technologies, Faculty of Agronomics Sciences, University of Abomey-Calavi, Republic of \\ Benin. \\ ${ }^{2}$ Central hospital of the health zone Adjohou-Bonou-Dangbo, Ministry of Health, Cotonou, Benin. \\ ${ }^{3}$ Joint Research Unit in Nutrition and Food, RDC-Nutrition AFRA/IAEA, Ibn Tofaïl University-CNESTEN, Morocco.
}

Abstract. This study is part of the national programme for the promotion of exclusive breastfeeding (EBF) and was technically supported by the International Atomic Energy Agency. It aimed to determine the factors leading to the cessation of EBF among mothers living in areas benefiting from an important breastfeeding promotion actions in southern Benin. The practice of EBF was measured using "deuterium oxide dose to the mother" technique in 105 mothers during 6 month's post-partum. Factors influencing the duration of this practice were investigated through an individual interview with the mothers and their relatives. The prevalence of EBF practice in lactating mothers was $58.7 \%, 29.1 \%$, and $2.4 \%$ at 1,3 , and 6 months postpartum respectively. The main factor favoring this practice at 1 and 3 months was sufficient breastmilk supply. Continuation up to 6 months was due to the support of the family and belief in its benefits. On the other hand, the principal factors that led to its interruption at 1 and 3 months were insufficient breastmilk production and the giving of herbal teas and water to the babies. After 6 months, the drastic drop of EBF was due to the lack of the support from fathers. Integrating these factors into EBF promotion actions might increase practice.

Keywords: Exclusive breastfeeding practice, factors influencing, Benin

\section{Introduction}

Breastfeeding is the best way to provide ideal nutrition for proper infant growth and development [1]. Optimizing breastfeeding practices through exclusive breastfeeding (EBF) for up to six months offers the best chance of improving child survival and contribute to prevent the 1.4 million under-five deaths that occur in developing countries [2]. Indeed, EBF has a significant impact on infant nutrition, overall child mortality particularly from infectious and nutritional causes [3]. In Benin, the prevalence of stunting was $32 \%$ attributed mainly to poor nutrition in the first 6 months of life [4].

Despite numerous advocacy and implementation initiatives, the prevalence of EBF practice remains low in many countries and declines from the first to the second postpartum trimester [5-7]. In Benin in 2018 and based on mothers' report, the prevalence of EBF was $42 \%$ and it was noted that $28 \%$ of children had received, in addition to breast milk, water and $12 \%$ complementary foods before the sixth month of age [4]. The low prevalence of $\mathrm{EBF}$ in most developing countries is attributed to various factors [8] meanly related to the mother's health status, residence area, EBF practice understanding, the child's sex and age, as well as the family environment (spouse, mother or mother-in-law, friends and household size) [5, $9,10]$. Usually in the case of national surveys the prevalence of EBF is determined according to the mother reporting by using a 24-hour recall questionnaire. A method which, although proven, is nevertheless dependent on the respondent's answers [11, 12]. Thus, it introduced a significant bias both on the classification of breastfeeding practices and on the identification of the associated influencing factors. In order to avoid this classification bias, the choice of the method to assess EBF is crucial. Nowadays the 'Dose-to-Mother' deuterium oxide dilution technique (DOD) seems to be the most accurate and objective method to assess EBF without interfering with normal feeding practices [13]. Otherwise, for almost a decade, several regions in Benin benefited from numerous EBF-promoting interventions namely Nutrition at the Centre Phase 1 and 2, Community Nutrition Programme Multisectoral Food, Health and Nutrition Programme $[14,15]$. However, the acceptance that the mother practices the EBF throughout the recommended 6-months period faces an important barrier reflected in its low prevalence despite all intervention actions. Thus, the aim of this study is to determine the real brakes on the EBF practices at each age group in order to provide evidence for greater effectiveness and efficiency of nutrition programmes focused on increasing this practice in this country with high stunting prevalence.

\section{Methodology}

\subsection{Study design}

This is a longitudinal study based on two approaches. The quantitative study measured the rate of EBF at 1 month, 3 months and 6 months postpartum by using deuterium oxide dose to the mother technique and the qualitative study analyzing the factors associated with not continuing this practice by interviewed focus groups. The follow-up study took place from June 2019 to December 2019 and was conducted in the Adjohoun-Bonou-Dangbo (ABD) region, which has been benefited for nearly a decade from numerous EBF promotion interventions [14-17]. For the purpose of the quantitative study, 105 pairs mother/baby were enrolled (lactating mothers with babies aged one month who agreed to participate in the study were included. Excluded were mothers or babies who suffering from diseases requiring hospitalization, mothers with multiple births and mothers under 16 years old and nonresidents in community). After data clearance [13], we had 92 pairs mother/baby at 1 month, 86 at 3 months and 84 at 6 months respectively. Based on the results of this follow-up, the breastfeeding mothers were categorized according to the duration of EBF: mothers who did not practiced EBF, mothers who stopped EBF at 1 month of

\footnotetext{
*Corresponding author: jahdielkossou@gmail.com
} 
child age and mothers who stopped EBF at 3 or 6 months of child age. For the purpose of the qualitative study, mothers and their collaterals were interviewed during the beginning of 2020 and a random selection was made at each mothers group [18] to make the focused groups. The table 1 resumes the composition of each focused group. Indeed, a total of 70 participants, were interviewed (35 mothers, 20 fathers, 10 grandmothers and 05 midwives).

Otherwise, before starting the field survey, the agreement of the national ethics committee for health research was obtained as well as the authorization to conduct the study from the coordinating Doctor of the $\mathrm{ABD}$ region (CR $\mathrm{N}^{\circ} 16$ of $04 / 11 / 2019$ and $\mathrm{N}^{\circ}$ 47/MS/DC/SGM/DRFMT/ CNERS/SA on 06/11/2019).

Table 1. Summary of target groups for the determination of associated factors

\begin{tabular}{llllll}
\multicolumn{7}{c}{ EBF: exclusive breastfeeding } \\
$\begin{array}{l}\text { Categories } \\
\begin{array}{l}\text { Narget } \\
\text { groups }\end{array}\end{array}$ & $\begin{array}{l}\text { EBF } \\
\text { Mother }\end{array}$ & $\begin{array}{l}\mathbf{1} \\
\text { month }\end{array}$ & $\begin{array}{l}\text { EBF at } \\
\mathbf{3} \\
\text { months }\end{array}$ & $\begin{array}{l}\text { EBF at } \\
\mathbf{6} \\
\text { months }\end{array}$ & Total \\
\hline Father & 03 & 07 & 09 & 01 & 20 \\
\hline $\begin{array}{l}\text { Grandmot } \\
\text { her }\end{array}$ & 03 & 03 & 02 & 02 & 10 \\
\hline Midwives & 05 & 00 & 00 & 00 & 05 \\
\hline Total & 22 & 22 & 21 & 05 & $\mathbf{7 0}$ \\
\hline
\end{tabular}

\subsection{Data collected}

\subsubsection{Socio-demographic questionnaire}

Socio-demographic information, including data on economic status, education, parity, antenatal visits (ANC) and dietary diversification [19] was collected. The socioeconomic status of households was calculated on the basis of goods and materials that the household owns [20].

2.2.2 Assessment of breastfeeding practice using 'Dose-to-Mother' Deuterium Oxide Dilution Technique (DOD)

The practice of exclusive breastfeeding was measured using DOD as detailed by IAEA standard procedure [13]. A dose $(30 \mathrm{~g})$ of deuterium oxide $(99.8 \%$ purity) was administered orally to the mothers after initial saliva sampling of the mother-infant pair (D0). Further saliva samples were collected at days 1, 2, 3, 4, 13 and 14 after dosing [13]. Using small pieces of cotton wool, saliva samples of approximately $2 \mathrm{ml}$ were collected in cryovials and transported to the laboratory to be stored at $-20^{\circ} \mathrm{C}$ until analysis. The tubes of saliva samples were clearly labelled with the date and time of collection and the participants' codes. Deuterium oxide enrichment in the saliva samples was measured using an Agilent $4500 \AA$ series Fourier transform infrared spectrophotometer (FTIR). This technique allows accurate quantification of human milk intake and water from other sources than breast milk. Thus, the mothers were considered practicing exclusive breastfeeding if their child's intake of water from sources other than breast milk was less than $86.6 \mathrm{~g} /$ day [21].

\subsubsection{Determination of factors associated to the} cessation of the practice of exclusive breastfeeding

A semi-structured focus group interviews according to the Social Analysis and Action (SAA) approach was followed [22] to understand the explanatory factors (favourable or unfavourable) of the practice of EBF at a time of its cessation. However, given the Covid 19 pandemic and it constraints, the focused groups interviews were conducted by telephone with a recorder. The discussions were conducted in the local vernacular "Goun" then transcribed into Word and translated into French. This involved a double transcription of the data and a translation by linguists in order to limit errors. The data, which was transcribed and translated, was then analyzed by thematic content in order to obtain and classify the information from various angles that could be exploited [23]. The content analysis was done in reference to the scientific elements who appeared in the text, namely: the characterization, classification and enumeration of the elements that constitute the meaning of the text. This content analysis of the transcript had two phases: the categorization phase, which had made it possible to draw up a catalogue of recurrent elements in the transcripts made. The inference phase, was used to interpret the recurring elements identified during the categorization phase [23].

\subsection{Statistical analysis}

The assessment of the exclusivity of breastfeeding practices was done via the determination of non-milk water intake which is calculated by using a specific excel sheet developed by IAEA [24, 25]. The pair mother/baby whose non-milk water intake is less than $86.6 \mathrm{~g}$ /day was considered practicing exclusive breastfeeding. All data collected on socio-demographic characteristics, breastfeeding practices were entered and processed with SPSS software. The frequencies and numbers of categorical variables were determined according to breastfeeding type and group. The proportions of the participants' perceptions were detected and put into verbatim form.

\section{Results}

\subsection{Characteristics of breastfeeding mothers}

The mean age of the mothers was $28.3 \pm 5.6$ years and they had an average of 3 children, $52.2 \%$ of these children were girls. Most of the mothers lived in polygamous households and $51.1 \%$ of them had received formal education (table 2).

Table 2. Maternal characteristics $(n=92)$

\begin{tabular}{lll}
\hline Variables & Modality & Value (\%) \\
\hline \multirow{2}{*}{ Sex of children } & Female & $48(52.2)$ \\
\cline { 2 - 3 } & Male & $44(47.8)$ \\
\hline Economic status status & Single & $8(8.7)$ \\
\cline { 2 - 3 } & Monogamous & $37(40.2)$ \\
\cline { 2 - 3 } & Polygamous & $47(51.1)$ \\
\cline { 2 - 3 } Food diversification & Rich & $67(72.8)$ \\
\cline { 2 - 3 } & No & $25(27.2)$ \\
\hline Formal education & Yes & $25(27.2)$ \\
\cline { 2 - 3 } & Yes & $67(72.8)$ \\
\hline $\begin{array}{l}\text { Mother's age in years } \\
\text { (means } \pm \text { SD) }\end{array}$ & & $47(48.9)$ \\
\hline Parity (means \pm SD) & & $28.3 \pm 5.1 .6$ \\
\hline $\begin{array}{l}\text { Number of antenatal } \\
\text { consultations (means } \\
\pm \text { SD) }\end{array}$ & & $3.2 \pm 1.6$ \\
\hline
\end{tabular}


About $72.8 \%$ of the breastfeeding mothers lived in a poor household and $50 \%$ of them had trade as their income activity. They had attended an average of $3.5 \pm 1.2$ antenatal consultations and $72.8 \%$ of them had a diversified diet.

\subsection{Prevalence of exclusive breastfeeding practice}

The prevalence of EBF practice in lactating mothers was $58.7 \%, 29.1 \%$, and $2.4 \%$ at 1 month, 3 months, and 5 months postpartum, respectively. These results showed that the practice of EBF decreased over time in lactating mothers. There were only 2 lactating mothers who continued the practice of EBF from the birth until 6 months of baby's age (figure 1).

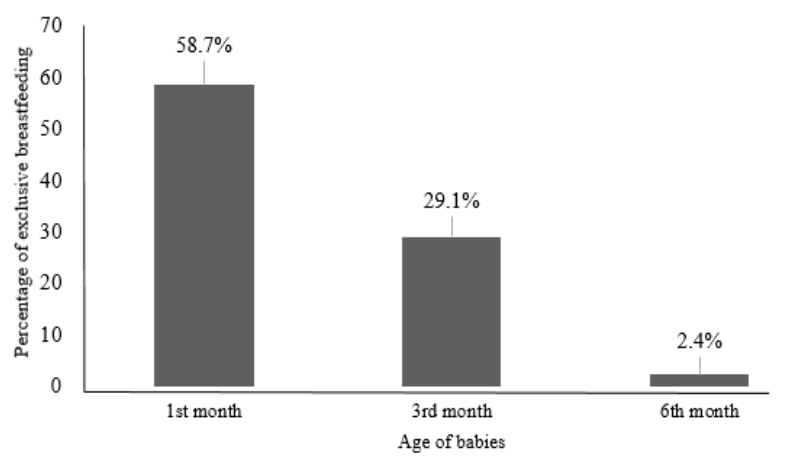

Figure 1. Rate of exclusive breastfeeding from 1 to 6 months of babies.

\subsection{Breastfeeding practices of mothers according to diet diversity and education}

Mothers who had carried out EBF for 06 months had a diversified diet and a higher number of prenatal consultations (4 ANCs) and all of them had received formal education. In contrast, in the other practice groups, only $50 \%$ had formal education and 3 ANCs.

3.4 Assessment of factors supporting exclusive breastfeeding according to the age of child (1 month, 3 months and 6 months)

3.4.1 Factors favoring exclusive breastfeeding during 1 month and 3 months

According to $50 \%$ of mothers who had undergone EBF up to 1 month, the mother's good diet promoted a good milk supply, making the milk available for the baby. However, 2 of mothers stated that the advice and the monitoring of health workers was the key to encourage or not their practice of EBF to 1 month. For mothers who completed EBF until 3 months, the principal factors to continue this practice were attributed to sufficient and adequate food in the house, $50 \%$ of them had added that the advices and the monitoring of midwives at the hospital and during the awareness sessions were also a major source of motivation. However, $20 \%$ of mothers felt better able to give their child only breast milk, and this on a permanent basis throughout the 3 -months period.

\subsubsection{Factors favoring exclusive breastfeeding until 6 months}

The reasons given by the mothers who practiced exclusive breastfeeding over the 6 months to explain their determinations and their various sources of motivation in this practice are of various origins. Indeed, the mothers considered the support of the persons of their entourage (the husband, grandmother, relatives...) as a determining factor. In addition, they stated that "being in a monogamous household and living with their husbands away from the in-laws was a factor in favor of the practice". They also mentioned that the husbands strongly encouraged them to avoid any additional food sources than breastmilk: "the child's father said no to giving him herbal tea or water, so I had no choice". Also their previous experiences with their first children showed that the children who have been exclusively breastfed had better health and they also noticed that "sucking the nipples favored and stimulated more lactogenesis".

3.5 Assessment of factors limiting exclusive breastfeeding at birth, 1 month and 3 months

3.5.1 Factors limiting exclusive breastfeeding practices at birth

According to more than half of the mothers (54.5\%), the main cause of not exclusive breastfeeding is the early introduction of water in the infant's diet. The mothers affirmed, that due to their various occupations, they entrusted their children to neighbors, who were given water to the baby without the knowledge of mothers. The other mothers mentioned that the perception of constant thirst, hiccups or continue baby's crying observed by them, the fathers or relevant, prompt them to give water to the children to calm them down or because they thought that they don't have enough milk. Some mothers said about their husband: "he himself went to the market to buy the battled water to the child".

Others mothers $(27.3 \%)$ stated that they gave the child herbal tea because of stomach-ache the child was suffering from or because of cultural and cultic reasons: "we should give certain specific herbal teas to the child from birth to prevent misfortune".

\subsubsection{Factors limiting exclusive breastfeeding at 1} month

Regarding the factors limiting the practice at 1 month, the majority of the mothers surveyed had given their children water, $66.66 \%$ said that they had followed the advice of family and friends to introduce water because "breast milk alone was no longer sufficient and the child would not stop crying". Moreover, they stated: "when the child sees that we are drinking water, he is interested in the bowl, which shows that he wants some, so I give it to him". A percentage of $40 \%$ of mothers surveyed, said that they had given compounds in the form of herbal tea or medicine because the child did not feel good from their saying: "sometimes children's stools have a strong unpleasant odor, so we prepare herbal tea for them to cleanse their stomachs". "The child was coughing or had fever and when we took him to the hospital, the doctors or the health workers prescribed medicine that I gave him with water". 3.5.3 Factors limiting exclusive breastfeeding to 3 months

As observed previously, the administration of water was associated in many cases with the child crying or the child feeling thirsty. Some mothers focused their arguments on the influence of the relevant to introduce food or herbal tea at an early age in cases where children are left in the care of another person. Only $20 \%$ of mothers reported that the child was sick at this age. 


\subsection{Fathers', Grandmothers' and midwives knowledges and perceptions of EBF}

3.6.1 Fathers' perceptions and involvement in the practice of exclusive breastfeeding

Fathers were categorized according to the mothers' breastfeeding practices. Very few $(20 \%)$ fathers were truly aware of the benefits of EBF, and supported the mothers in this practice. They hardly ever have attendance at pre or post-natal consultations and were often outside the household when facilitators from community nutrition projects in the area were visiting households. This was noticed in the quote: "I don't have time to go to the hospital, my concern is the daily bread".

Mainly associated with infants crying, fathers recommend that mothers give liquids other than breast milk (water, fruit juice and herbal tea) and justifying this by saying: "that was the way with us, I've been taking the tea since I was born and look at me, I'm doing well". On the other hand, when the father is sufficiently involved and convinced of the benefits of EBF, we note an increase in the duration of practice, as detected at 6 months in the case of those who practiced EBF over the entire period. 3.6.2 Grandmothers' perceptions and involvement in the practice of exclusive breastfeeding

Although a large proportion $(80 \%)$ of the grandmothers praised the advantages of EBF for the child's well-being, it is clear that the notion of breastfeeding is accepted, but the notion of exclusivity was not well understood and accepted. Indeed, the grandmothers surveyed mentioned the disadvantages of exclusivity, stating that water is essential for the child because if the child does not learn to drink water from a young age, he or she will not drink well when they grow up. They said: "when the child finished to breastfeed, his throat is dry and thirsty, so we should give him water to comfort himself "and" he can take a small glass of water to feel well". Moreover, for the grandmothers: "the child's cries pushes us to give him water, when he cries, we give it to him and he calms down".

\subsubsection{Knowledge and perceptions of midwives on the practice of $E B F$}

The health workers, although convinced and sufficiently aware of the benefits of EBF. However, they found reasons for mothers to stop exclusive breastfeeding. The mean reason was, "after the first three months, it becomes complicated to practice EBF because the mothers have to work and go to the marketplace in their villages to sell their products". "Mothers can do mixed breastfeeding after three months, they just have to choose clean milk products". The midwives also confirmed the absence of the support in the household, particularly from fathers. At the health center, they raised the insufficiency in the organization and regularity of communication sessions toward mothers during prenatal consultation. On the other hand, more regular communication was notified by the midwives during the infant vaccination sessions but by this time the mother had already adopted a breastfeeding mode.

\section{Discussion}

The aim of this study was to monitor the practice of EBF during the first 6 months of life of the infant and to determine the factors associated with the duration or the cessation of this practice in breastfeeding mothers. During the first month, over half of the women were practicing EBF (58.7\%) and this fell at 3 months (29.1\%) and even more at 5 months $(2.4 \%)$. This proportion was much lower than that of the Demographic and Health Survey (DHS) in Benin or in Mali (41\%, 30.7\% respectively) using mother report $[4,26]$. The difference would be due to the Deuterium Oxide Dilution Technique (DOD), which is a rigorous method for detecting mothers who have actually done the EBF [13], and to the decline in the practice of EBF, which is increasing over time in many countries [27-30]. The particularity here is that this drop is very significant at 6 months, where it is $2.4 \%$. It is slightly higher than in Botswana where it was $0 \%$ [27] and is clearly lower than the $30 \%$ in Morocco [30] using the same DOD method. This drop from $58.7 \%$ at 1 month to $2.4 \%$ at 6 months is very intriguing in an area with high promotion of EBF and raises questions about the reasons for this cessation.

Our study showed that the mothers who practiced EBF up to 6 months had all received a formal education. The association of mothers' education to the practice of EBF has also been demonstrated in different study making clear that at its own a high level of schooling would support the practice of EBF [31-34]. Also, and according to the mothers, we have identified two other limiting factors: a good access to a diversified diet and the number of antenatal visits. Indeed, the mothers who had a good access to a diversified diet, believe that they will produce more milk and these mothers who exclusively practiced EBF up to 6 months had the highest number of antenatal visits (04). A similar pattern was noted in Mali and Egypt $[26,35]$, where mothers who had made fewer antenatal visits practice less EBF than those who had made four (04) or more antenatal visits. On the other hand, it seems that the mothers who continued the EBF up to 6 months were multiparous unlike those primiparity. Indeed, the multiparous mothers had more experience and a higher level of self-confidence and self-efficacy which seems to be in favor of EBF practice [36, 37].

Other major factor influencing the breastfeeding practice is the implication of the father, relevant and the mother's entourage. Indeed, in Benin, being in a patriarchal regime [38], the father's agreement and support is preponderant in resurrecting any initiative in the child. Fathers who were uninformed and unconvinced of the benefits of EBF ordered mothers to give water or herbal teas to the child to calm the crying child or cure illnesses. Fathers' support is crucial for successful breastfeeding and the lack of spousal support was identified as a barrier to the EBF practice in many other study [39-42]. In addition, in our study health workers revealed that the non-involvement of husbands in antenatal consultations means that they have little knowledge about the benefits of the breastfeeding and the opinion of the baby's father could support or discourage a woman's decision on continuing breastfeeding [43]. 
Otherwise, and particularly when the mother entrusts her child to another person, the latter will feed the child with water or other food to calm crying or hunger or perception of thirst, without notifying to the mother. In addition, they influence mothers' practices by advising them to introduce other liquids than breast milk at an early age. These results are in line with other studies that have shown that the beliefs and representations of the entourage about breastfeeding, the socio-cultural pressure to introduce water or herbal tea in the infant's diet have greatly influenced the practice of EBF [44-46].

Insufficient breastmilk was also one of the reasons given by mothers to not respecting exclusive breastfeeding which was raised by different previous study in other countries like Tunisia and Kenya [47-50]. This insufficient milk could be explained by the mothers' undiversified diet or the state of health after delivery and the stress. However, a few mothers are aware that increased suckling is a corrective to insufficient milk production [2].

Finally, the lack of organization of EBF awareness sessions and the imprecise period of introduction of complementary food advised by the health workers ( 4 months for some agents and 6 for others) negatively influence the practice of EBF up to 6 months. This has already been noted in Benin and was the source of confusion and misperception of mothers about the duration and good practice of the EBF [51].

Thus, it seems that the problem of the cessation of exclusive breastfeeding has several and various factors. Indeed, the implication of well-informed father, relevant entourage and health workers on good breastfeeding practices, a good dietary diversification and health worker monitoring would improve the practice of EBF and also controlling the factors limiting this practice particularly cultural and cultic factors [5, 9, 10, 41, 47].

Although, the use of the DOD method in monitoring the practice of EBF is a strength of the study. Due to COVID-19 Context, all interviews with mothers, relevant, fathers and midwives were done by phone calls which led to a reduced numbers of participants in interviewing groups and also the participants can be less precise than direct interview thus constituting a major limit of the study.

\section{Conclusions}

The rate of exclusive breastfeeding during the first six months of life of children from areas with high promotion of EBF was very low. The factors that influenced this practice were mainly related to the support and involvement of mother's entourage, her sociological characteristics, the pregnancy monitoring, and the diversified diet. In addition, the notion of breastfeeding is accepted but the notion of exclusivity was poorly understood by the mothers and their families. Thus, focusing interventions to promote EBF on raising the awareness of the family and friends, the effective involvement of fathers, the instruction of mothers, the diversification of food and the monitoring of health workers would make it possible to improve the practice of EBF.
Acknowledgements. The technical support of the International Atomic Energy Agency is gratefully acknowledged. We thank the International NGO CARE Benin/Togo, for its partial financial support. We would like to thank the mothers and infants who participated in the study.

\section{References}

1. OMS. Exclusive breastfeeding. (2020) [Consulted 26 December2020]:http://www.who.int/nutrition/topics /exclusive breastfeeding/fr/.

2. UNICEF. Bienfaits de l'allaitement précoce sur les nouveaux nés (2020). [Consulted 26 December 2020]:http://www.unicef.org/apps/newsfr/storyF.asp

3. M. Kramer, B. Chalmers, E.D. Hodnett, Z. Sevkovskaya, I. Dzikovich, S. Shapiro. Jama. 285, 4 : 413-420. (2011)

4. INSAE et ICF. EDSB, 2017-2018 Bénin. p 1-675. (2019)

5. N. Jama, A. Wilford, Z. Masango, L. Haskins. Int. Breastfeed. J. 125, 1: 431-13. (2017)

6. S. Tchenar, H. Boumedine. Mémoire de fin d'étude pour l'obtention du diplôme de docteur, Algérie. (2017).http://193.194.84.142/theses/psychologie/BO $\underline{\mathrm{U} 876 . \mathrm{pdf}}$

7. K.E. Agho, M.J. Dibley, J.I. Odiase, S.M. BMC Pregnancy and Childbirth. 11, 1:2. (2011)

8. A. Jama, H. Gebreyesus, T. Wubayehu. Int Breastfeed J. 15, 5 (2020).

9. C. Dennis. J Obstet Gynecol Neonatal Nurs. 31, 1:1232. (2002)

10. E. Peters, K.H. Wehkamp, R.E Felberbaum. Eur J Public Health. 16, 2:162-7. (2006)

11. T.M. Samuel, T. Thomas, S. Bhat \& A.V. Kurpad. Eur. J. Clin. Nutr. 66(4), pp. 459-465.

12. Motswagole B. et al., South Afr J Clin Nutr. 28, 3 : 128-133. (2015)

13. AIEA. Human Health Series $n^{\circ} 7.88$ pp. (2014)

14. CARE International. Nutrition at the Centre (2018). [Consulted 31 Mai 2021]: https://nutritionatthecenter.wordpress.com/about.

15. CAN Bénin. Stratégie nationale de communication pour le changement social et comportemental pour la promotion de la nutrition au Bénin et son plan opérationnel. 120pp. (2016)

16. Care International Bénin- Togo. Capitalisation de la Nutrition au Centre (N@C) et de Protéine pour la Population. p 179. (2019)

17. Conseil de l'Alimentation et de la Nutrition du Bénin. Présentation du PMASN et rôles des équipes de terrain des ONG. p 29. (2017)

18. Gaspard Claude. Le focus group: caractéristiques, utilisation et exemple. [Consulted 20 November 2019] https://www.scribbr.fr/methodologie/focusgroup/

19. Y. Martin-Prevel, M. Arimond, P. Allemand, D. Wiesmann. Curr Dev Nutr, 1. (2017)

20. INSAE Benin - Enquête par Grappes à Indicateurs Multiples. (2014).

21. S.E. Moore, A.M. Prentice, W.A. Coward. Am. J. Clin. Nutr. 85, 1075-1082. (2007)

22. CARE. Manuel global d'implémentation $d u$ processus Analyse et action sociales. p177 (2015) 
23. P. Wanlin. L'analyse de contenu comme méthode d'analyse qualitative d'entretiens. Université du Luxembourg. p 224-272. (2007).

24. Z. Liu, A. Diana, C. Slater, T. Preston, R.S. Gibson, L. Houghton. J. Pharmacokinet Pharmacodyn. 46, 113 (2019).

25. C. Slater, P. Kaestel, L. Houghton. Ann. Nutr. Metab. 75 : 109-113 (2019).

26. M. Traoré, H. Sangho, M.D. Camara, A. Faye et al. Santé publique. 26, 2:265. (2014)

27. B.S Motswagole, T. Mongwaketse et al,. S Afr J Clin Nutr. 28, 128-133. (2015).

28. G.A. Ettyang, W.D. Van Marken Lichtebelt et al,. Ann Nutr Metab. 49, 110-117. (2005)

29. G. Choua, K. EL. Kari, N. Haloui, C. Slater, H. Aguenaou. IJMA. 1, 3: 45-50. (2013)

30. R. Baha, B. Kaoutar, I. Mohamed, R. Anass et al . Nutrients. 13, 1: 146. (2021)

31. A.L. Kristiansen, B. Lande, N.C. Øverby. Public Health Nutr. 13, 1:2087-2096. (2010)

32. T. Amin, H. Hablas, A. Qader. Breastfeed Med. 6, 2:59-68. (2011)

33. R.J. Blyth, D.K. Creedy, C.L. Dennis, W. Moyle, et al. J Hum Lact. 20, 1:30-8. (2004).

34. H. Kronborg, M. Vaeth. Scand J Public Health. 32, 1: 210-6. (2004)

35. M. Ghwass, D. Ahmed. Breastfeeding Med. 6, 4:19195. (2011)

36. P. Bougerraf, S. Hajjem, L. Guilloud. Arch Pediatr. 1998. 5, 1: 621-6.

37. F. Marrakech, A. Mzid, M. Elleuchs. Rev Magh Ped, p 5-6. (1995).

38. Loi $\mathrm{N}^{\circ} 2002-07$ Portant Code des personnes et de la famille en République du Bénin

39. R. Shirima, T. Greiner, E. Kylberg. Public Health Nutr. 4, 2: 147-154. (2001)

40. G.E. Otoo, A.A. Lartey, R. Pérez. JHL. 25(1): 34-41. (2009)

41. B. Gijsbers, I. Mesters, J. AKnottnerus J.A., A.H. Legtenberg et al. Patient Educ Couns. 57, 1: 15-21. (2005)

42. S.K. Kong. J. Adv. Nurs. 46, 4: 369-379. (2004)

43. M.E. Bentley, D.L. Dee and J.L. Jensen. Nutr. 133, p 3055-3095. (2003).

44. A.K.A. Diji, V. Bam, E, Lomotey A., Yeboah S., Owusu H.A. Int.Breastfeed.J. 12, 1: 131-7. (2017).

45. D.V. Duong, C.W. Binns, A.H. Lee. Public Health Nutrition. 7, 6:795-799. (2004)

46. T.S. Chandrashekhar, H.S. Joshi, V. Binu, P.R. Shankar et al. Public Health Nutr. 10, 2: 192-197. (2007).

47. S. Arora, C. Junkin, J. Wehrer, P. Kuhn. Pediatrics. 106, 1:51-5. (2000)

48. L. Gatti. J Nurs Scholarsh. 40 : 355-363. (2008)

49. T.K. Lubala, A.M. Mutombo, A.M. Nyenga, et al. Pan Afr Med J. 14, 1:142. (2013)

50. A. Matsuyama, M. Karama, J. Tanaka. BMC Public Health. 13, 1:525. (2013)

51. W. Amoussa Hounkpatin, S. Blum, A. Badou, A. Savi. Etude des déterminants des pratiques d'alimentation complémentaire des enfants de moins de 2 ans, Cas de 3 localités au Bénin : Boukoumbé, Djakotomey et Kétou, p371. (2014) 